\title{
Irreversible phenotypic perturbation and functional impairment of B cells during HIV-1 infection
}

\author{
Jingjing Yan*, Shuye Zhang ${ }^{*}$, Jun Sun, Jianqing Xu $(\bowtie)^{\mathrm{a}}$, Xiaoyan Zhang $(\bowtie)^{\mathrm{b}}$ \\ Shanghai Public Health Clinical Center \& Institutes of Biomedical Sciences, Fudan University, Shanghai 201508, China \\ (C) Higher Education Press and Springer-Verlag GmbH Germany, part of Springer Nature 2018
}

Erratum to Frontiers of Medicine 2017, 11(4): 536-547

https://doi.org/10.1007/s11684-017-0592-x

The original version of this article unfortunately contained a mistake. One of the authors of this article has been misspelled. Xiaoyang Zhang should be Xiaoyan Zhang. The update is also provided here.

The online version of the original article can be found at https://oi.org/ 10.1007/s11684-017-0592-x

Correspondence: axujianqing@shphc.org.cn;

bzhangxiaoyan@shphc.org.cn

*Jingjing Yan and Shuye Zhang contributed equally to this study. 